\title{
Myxomycete communities occurring in fragmented forest patches in two municipalities of Laguna, Philippines
}

\author{
J. L. M. Bernardoํ, L. J. Q. Arioder ${ }^{1}$, K. J. Almadrones-Reyes ${ }^{1}$ and N. H. A. Dagamac ${ }^{2}$ \\ ${ }^{1}$ Advanced Educational Program, Thai Nguyen University of Agriculture and Forestry, Quyết Thắng, Thái Nguyên, \\ Vietnam \\ 2Institute of Botany and Landscape Ecology, University of Greifswald, Soldmannstrasse 15, D-17487 Greifswald, \\ Germany.Author for correspondence: nhadagamac@gmail.com
}

Keywords: Fisher's alpha, Intermediate disturbance hypothesis, Microbial biodiversity, Plasmodial slime molds, S/G ratio, Species richness.

\begin{abstract}
In spite of the increasing number of myxomycete studies in the tropical Southeast Asia over the last decades, many forest patches are still left unexplored for the region, in particular in the Philippine archipelago. Thus, an assessment of myxomycete diversity, occurrence, and composition was carried out in forest fragments from two municipalities of the province of Laguna, Philippines. From the 12 established $5 \mathrm{~m} \times 5 \mathrm{~m}$ plots, a total of 240 moist chamber cultures were prepared for this study and yielded 42 myxomycete species belonging to 14 genera. Rarefaction curves and several heterogeneity indices revealed higher species diversity in Los Baños than in Calauan. Moreover, the taxonomic diversity index also showed that the taxonomic diversity of myxomycete in Los Baños is more intuitively diverse than in Calauan. In terms of community analysis between the two municipalities, it showed that myxomycete communities clustered between different microhabitats. High values of coefficient of community and percentage similarity indices possibly implicates that spore dispersal in forest fragments in closer proximities may cause high number of shared species (60\%). With an addition of Cribraria lepida as a new record for the country, this study now updates the myxomycete profile for Laguna, Philippines.
\end{abstract}

Nomenclature: See Table 1.

Abbreviations: A-Abundant, AIC-Akaike Information Criterion, BIC-Bayesian Information Criterion, C-Common, CCCoefficient of Community, O-Occasional, PS-Percentage of Similarity, R-Rare, SAC-Species Accumulation Curve, SADSpecies Abundance Distribution.

\section{Introduction}

General patterns of community structure for terrestrial macroorganisms are relatively well-known, but similar information on microorganisms remains patchy and limited mainly due to their small size, unique life cycle, and dispersal capacity (Martiny et al. 2006, Novozhilov et al. 2017). Fortunately, the mathematical methods of community ecology can still be applied to studies of myxomycetes using the morphological species concept. Furthermore, it was only in the 1980s when the first comprehensive ecological studies were carried out, analysing the occurrence of fruiting bodies in relation to environmental gradients, which includes the first studies of niche breadth and niche overlap (Stephenson 1988, Rojas et al. 2008). Approximately only $60 \%$ of all myxomycete morphospecies can be detected in the field, while the remaining percentage needs moist chamber culture techniques and examination using microscope. But recently, ecological studies of myxomycetes were limited by the detection and identification of the fruiting bodies. With that, the challenge now in tropical settings is to determine the factors i.e. forest structure, disturbance history that constrains species distribution. Ecological niches were applied as the main theoretical concept for myxomycete distribution studies (Soberón 2007, Broennimann et al. 2012) using habitat and microhabitat as its describing parameters. Even though macroclimate and habitat limits the myxomycete distribution, there is strong evidence that microhabitat availability is the factor strongly affecting their species distribution (Rojas and Doss 2014).

Myxomycetes (also known as plasmodial slime molds or true slime molds) are phagotrophic eukaryotes, abundantly thriving in terrestrial ecosystems (Dagamac et al. 2010, Kuhn et al. 2013, Massingill and Stephenson 2013, Dagamac et al. 2015a). Morphologically, there are ca. 1000 species known and described worldwide (Lado 2005-2018). They are usually reported from many forested regions of the world, especially in areas with a mass of decaying logs, twigs, and leaf litter (Rojas and Stephenson 2013, Redeña-Santos et al. 2017). Their placement in the Tree of Life became controversial due to their complex life cycle. Though they were once classified in the Kingdom Animalia, the Kingdom Plantae, and the Kingdom Fungi, they were recently classified in the Kingdom Protista (Amoebozoans) based on molecular evidences (Fiore-Donno et al. 2010). In terms of their environmental role, they are neither pathogens nor decomposers but rather exist as "microbial predators" that consume many other microorganisms in their surroundings (Keller et al. 2008, Corpuz et al. 2012). Hence, they are considered to play an important role in maintaining the balance in soil ecosystem 
(Feest 1987, Foissner 1999, Stephenson 2011). Furthermore, insects also depend on slime molds for food (Keller and Snell 2002). However, despite its relevance to nature, studies of myxomycete biodiversity are still limited and unexplored, especially in the Southeast Asian Paleotropics where higher species diversity can be expected (Dagamac et al. 2014).

The Philippines is considered to be one of the world's most biologically rich tropical countries, but studies of myxomycetes are scarce (Dagamac et al. 2012, Rea-Maminta et al. 2015) although there was a significant increase in the number of studies about myxomycetes of the Philippines over the last decades. The earliest study of myxomycetes in the Philippines began when Uyenco (1973) claimed to have published the first report on Philippine myxomycetes. Here, she had successfully collected 314 specimens of myxomycetes from Luzon (Quezon City and Laguna) and Mindanao (Basilan and Zamboanga). But according to Dagamac and dela Cruz (2015), Dogma (1975) has stated that Martin and Alexopoulos (1969) had already credited the Philippines with 22 species in their book "The Myxomycetes". However, it was Don Reynolds (1981) who has successfully made the most remarkable findings of myxomycetes in the Philippines, after he reported a total of 107 species. Since then, surveys and publications about myxomycetes have remained stagnant for nearly 30 years (Dagamac and dela Cruz 2015). Apparently, new records for the country were reported during the last recent decade as several surveys, i.e. Anda Island (1 new species, Moreno et al. 2009), Lubang island (7 new records, Macabago et al. 2012), Mt. Arayat National Park (5 new records, Dagamac et al. 2012), Bataan and Mt. PalayPalay National Parks, Subic Bay Forest Reserve (19 new records, dela Cruz et al. 2014), Bicol peninsula (8 new records, Dagamac et al. 2017a) and Bohol islands (8 new records, Macabago et al. 2017), were conducted in the country. However, many places in the country have been exposed to increasing urbanization, deforestation and human population growth causing many secondary old growth forests in lowland provinces to become fragmented forest patches. These forest fragmentations may result in diversity degradation which may indicate changes on myxomycete diversity. This has been the major challenge not just for the locals, but especially for many conservation biologists and environmental scientists, as habitats tend to be highly affected, leading to the possible loss and non-documentation of many species including myxomycetes (Almadrones-Reyes and Dagamac 2018). This is precisely the case happening in the two municipalities of Laguna (Los Banos and Calauan) where industrial progress has explicitly increased almost every year. Therefore, this research study wanted to answer the questions: (i) What are the myxoymcete species found in fragmented forest patches in two municipalities (Calauan and Los Baños) of Laguna, Philippines? (ii) How diverse are the myxomycete species occurring from both municipalities? and (iii) How similar are the myxomycete assemblages between the two municipalities?

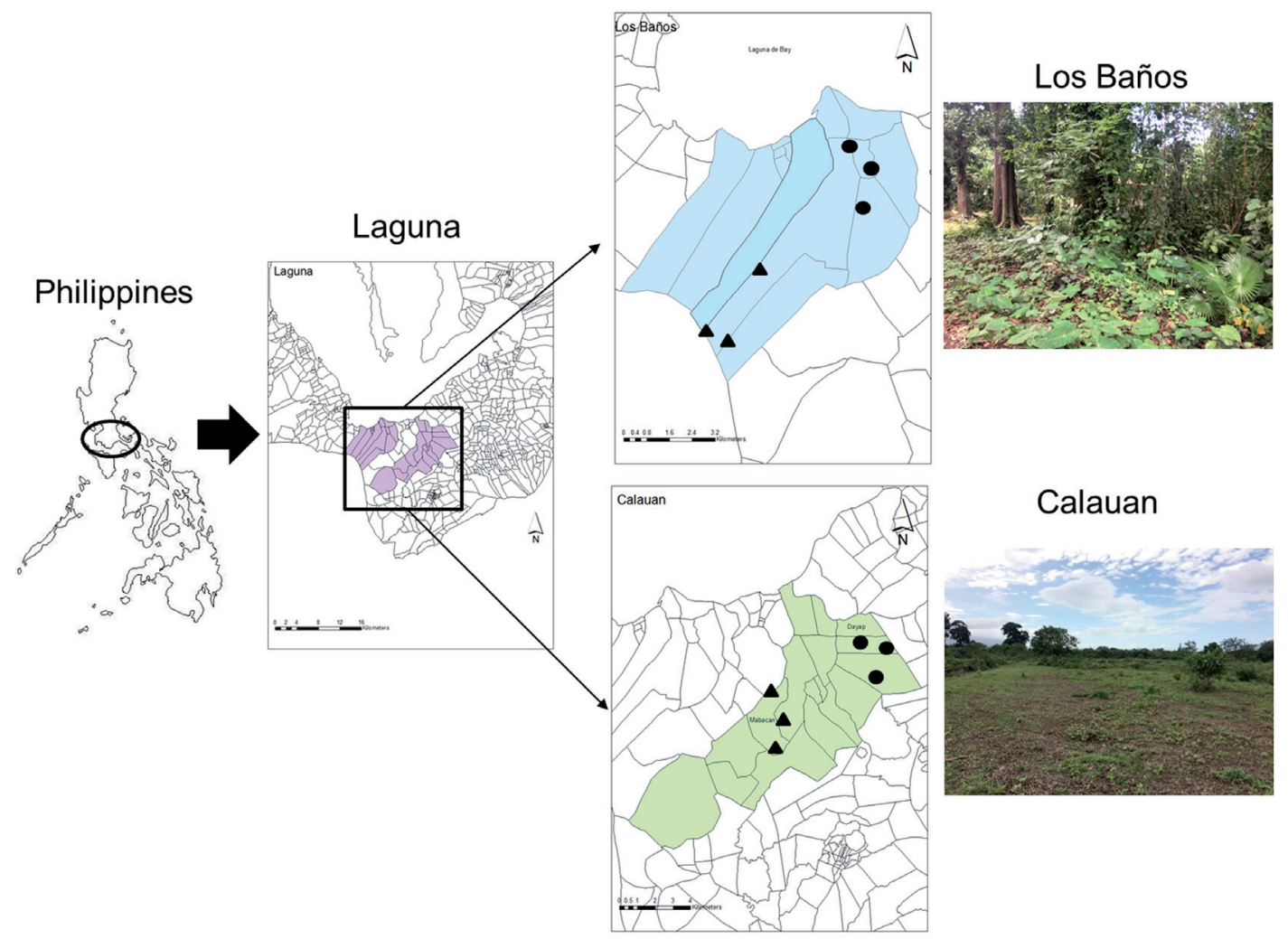

Figure 1. Map of the study area showing the two municipalities of Laguna. Each municipality has two collecting points (dots: first collecting point and triangles: second collecting point) with three collecting plots. 


\section{Materials and methods}

\section{Study site}

The province of Laguna (Fig. 1) belongs to the southern Luzon part of the Philippines. For convenience purposes, unmanaged lowland forest fragments (ca. $700 \times 700 \mathrm{~m}^{2}$ for each municipality) from two nearby municipalities were chosen as collecting localities for this study, namely, Los

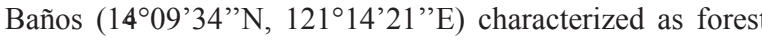
fragments that are moderately disturbed due to implementation of biological conservation of the government officials in their forest patches. Heterogenous plant vegetation composed of mostly tall dipterocarp trees such as Dipterocarpus spp., Shorea spp., and other vascular plants like Jatropha spp., Hevea spp. and Swietenia spp., made most of the collecting forest fragments of Los Baños to be generally described as closed canopy. In contrast, Calauan (1405'09' N, $\left.121^{\circ} 17^{\prime} 33^{\prime \prime} \mathrm{E}\right)$ collecting localities are located beside housing projects and corn plantation where anthropogenic disturbance are expected to be higher. Calauan has almost no canopy cover with most of the vegetation covered by weeds and grasses and only patchy single stands of local Catanopsis or Acacia trees are observed in the area. Both municipalities experience a tropical monsoon climate which is relatively dry during the month of November to April and wet during the rest of the year.

\section{Substrate collection}

From each of the two municipalities (Calauan and Los Baños), two collecting points with three collecting plots each were randomly chosen based on the accessibility of those points to be collected. Then, from each collecting points, three $5 \mathrm{~m} \times 5 \mathrm{~m}$ plot that were at least $20 \mathrm{~m}$ apart were established. Within the plots, five samples of each substrate (Aerial leaf litter, ground leaf litter, twigs and barks) were collected arbitrarily for a total of 20 samples per plot, 60 samples per collecting points, 120 samples per municipalities and 240 samples for the whole study. The collected samples were then wrapped in paper sheets and were immediately transferred in the laboratory, following the sample method of prior studies. Afterwards, moist chamber (MC) cultures were set up following the protocol of Stephenson and Stempen (1994). The MCs were maintained under ambient light conditions and at room temperature $\left(22-25^{\circ} \mathrm{C}\right)$. The MCs were then checked during Week 1, 3, 6, 9 and 12 for the presence of plasmodia and/or fruiting bodies. If the MCs dry out, distilled water was immediately added to keep the moisture of the culture.

\section{Characterization and identification of fruiting bodies}

Fruiting bodies that were present on the positive MCs were transferred to herbarium boxes and placed under freezing condition for at least 2 days to dry out. The fruiting body characteristics (type, shape, presence of lime, height, and color) were described and used for initial determination using a stereo microscope (Zeiss Stemi DV4). Then, microscopic characterizations were conducted by transferring a single fruiting body to slide with a drop of Hoyer's medium for final determination. After 24 hours, the slides with fruiting bodies were examined using a light compound microscope (Zeiss Axiolab Al).

\section{Data evaluation}

Initially, a moist chamber that exhibited either plasmodial and/or fruiting body growth was considered as a positive collection for myxomycetes, and thus, was noted as one positive record. The number of positive collections was counted and divided by the total number of MCs prepared, which was expressed as moist chamber productivity (Macabago et al. 2012). Species composition and occurrence were also determined. The relative abundance of each species was obtained by dividing the total number of collections for each species of myxomycetes by the total number of myxomycetes collected (Stephenson et al. 1993). An abundance index was then translated from the computed values as described by Stephenson et al. (1993): $<0.5 \%$ - rare (R); $>0.5 \%$ but $<1.5 \%$ - occasional (O); $>1.5 \%$ but $<3 \%$ - common $(\mathrm{C}) ;>3 \%$ - abundant (A). To estimate the extent how the survey was exhaustive in terms of species obtained from the moist chambers, the software program EstimateS (Version 9.1, 200 randomizations) was used to construct a species accumulation curve (SAC). The Chao 1 estimator results (an estimator for target richness for individual based data as such that one record of a species in a certain culture is considered as one individual) was then utilized in accordance with the protocols of Macabago et al. (2017) and Novozhilov et al. (2017). The estimated value for the percentage of completeness for each municipality was then calculated by dividing the actual number of species recorded by the mean number of species expected as estimated by the Chao 1 estimator. Coleman rarefaction values generated from EstimateS was then utilized to construct a rarefaction curve which shows the comparison of species richness between the two municipalities.

To calculate the taxonomic diversity between the two municipalities, the quotient of the number of species with the number of genera was calculated. Intuitively, a lower value indicates the more diverse biota since in principle a biota with species distributed among many genera is more diverse than a biota with species belonging to only few genera (Stephenson et al. 1993). Using the vegan package in R environment, species abundance distribution (SAD) model was constructed for each of the two municipalities following the concept of Wilson (1991) that suggested the following five models: Null (fits the broken stick model), Preemption (fits the geometric series or Motomura model), log-Normal, Zipf and Mandelbrot. SAD models is regarded as a vector of the abundances of all species found in the community where it describes the number of individuals observed for each different species found within a community (McGill et al. 2007). To evaluate which of the five models would be the "best" fit for the data, corrected AIC (Akaike Information Criterion) was selected. In comparing the models fitted based on maximum likelihood, the smaller the AIC and BIC, the better the fit. Similarly, Fisher's alpha for species richness and two heterogeneity indices (Simpson 
and Shannon index) that account for both richness and evenness, were generated. Then, boxplot was produced from the three diversity measurements to visualize the diversity between the two municipalities.

Community analysis was also performed using (i) hierarchical cluster analysis based on Bray Curtis similarity (Bray and Curtis 1957) and (ii) Venn diagram that showed the distribution of species between the two municipalities. Furthermore, two similarity indices from Stephenson et al. (1993) were computed: Coefficient of Community (CC) which considers the presence or absence of a species between two municipalities being compared and Percentage of Similarity (PS) index accounted for both presence and absence of a species and its relative abundance. The $\mathrm{CC}$ values range from 0 (no species are present in both communities) to 1 (all species are present in both communities) while the PS values range also from 0 to 1 and are interpreted that if the value is closer to 1 then the two municipalities being compared are highly similar in terms of species composition and abundance.

\section{Results}

Moist chamber productivity and survey completeness

A total of 193 out of 240 moist chambers ( $80 \%$ ) produced myxomycetes. From these positive moist chamber cultures, a total of 335 myxomycete records are found in this study, i.e. 300 were fruiting bodies and 35 were plasmodia. These records were divided to 166 (154 fruiting bodies and 12 plasmodia) and 169 (146 fruiting bodies and 23 plasmodia) representing the municipalities of Los Baños and Calauan, respectively. In spite of the higher sampling intensity from Calauan than in Los Baños, as shown by the constructed species accumulation curve (Fig. 2), the municipality of Los Baños (79\%) gave a higher percent completeness than Calauan (62\%).

\section{Composition and occurrence}

This study reported a total of 40 species belonging to 14 genera (Physarum [11 species], Perichaena [6], Comatricha [3], Didymium [3], Hemitrichia [3], Arcyria [3], Cribraria [2], Diachea [2], Diderma [2], Collaria [1], Dianema [1], Echinostelium [1], Lamproderma [1], and Stemonitis [1]). Furthermore, 2 distinct forms of Arcyria cinerea (dwarf form, Schnittler 2000; yellow form, Dagamac et al., 2017b) were classified as separate morphospecies in this study amounting now to a total of 42 species, of which 11 are classified as abundantly occurring, 6 were common, 9 were occasional and 16 were rare (Table 1). Using the RADFIT command in $\mathrm{R}$, the species abundance distribution model for Los Baños and Calauan both showed lower AIC values for the steep gradient Mandelbrot model that indicates (i) high abundance for high ranking species and (ii) low evenness (Fig. 3, Table 2).

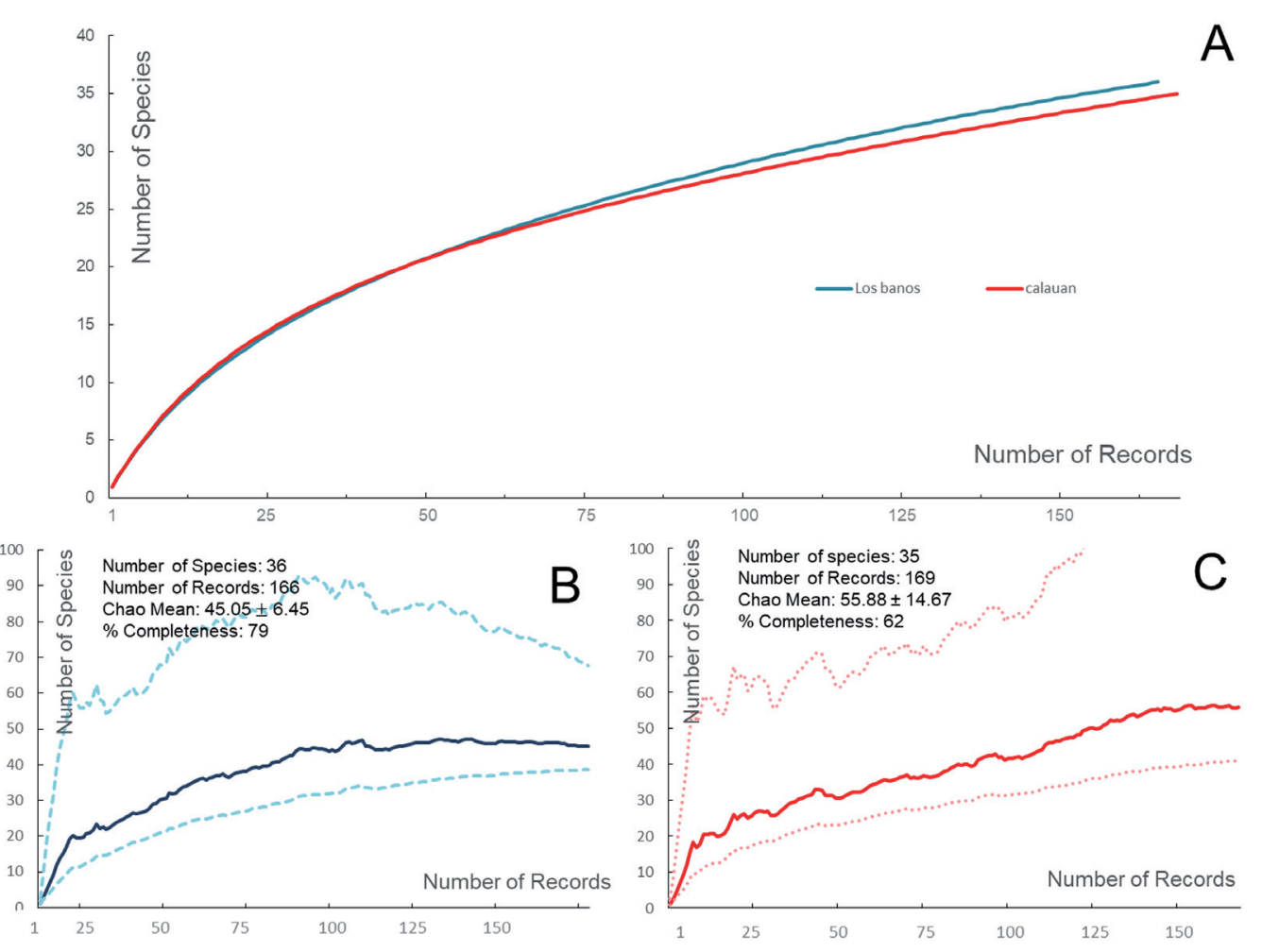

Figure 2. A) Rarefaction curve for the two municipalities and the generated sample based species accumulation curve based from Chao 1 estimator for (B) Los Baños and (C) Calauan. The thick line shows the Chao 1-mean, and the thin-dotted lines shows the $5 \%$ and $95 \%$ confidence interval. 
Table 1. Occurrence of myxomycetes in Laguna, Philippines. The table exhibits the alphabetically arranged list of myxomycete species and their respective $\mathrm{pH} \pm$, min-max as measured from every positive moist chambers where they are recorded. For species that occurred once (rare), only the $\mathrm{pH}$ value of that moist chamber is presented. The abundance index (AI) will represent the category of occurrence in accordance with Stephenson et al. (1993), ): $<0.5 \%$ - rare (R); $>0.5 \%$ but $<1.5 \%$ - occasional $(\mathrm{O}) ;>1.5 \%$ but $<3 \%$ - common (C); $>3 \%$ - abundant (A). Total number of records and its breakdown for each municipality, total number of species, and total number of genera were further reported in this table.

\begin{tabular}{|c|c|c|c|c|c|}
\hline Species & Total & $\begin{array}{l}\text { Los } \\
\text { Baños }\end{array}$ & Calauan & $\begin{array}{l}\text { Abundance } \\
\text { index }\end{array}$ & $\begin{array}{c}\mathrm{pH} \text { mean } \pm \text { standard error, } \\
\text { min-max }\end{array}$ \\
\hline Arcyria cinerea (Bull.) Pers. & 10 & 6 & 4 & A & $6.92 \pm 0.15,5.93-7.55$ \\
\hline Arcyria cinerea - dwarf (Bull.) Pers. & 4 & 2 & 2 & $\mathrm{C}$ & $6.52 \pm 0.21,5.93-6.91$ \\
\hline Arcyria cinerea - yellow (Bull.) Pers. & 10 & 8 & 2 & A & $7.35 \pm 0.12,6.76-8.07$ \\
\hline Arcyria denudata (L.) Wettst & 1 & 0 & 1 & $\mathrm{R}$ & 6.66 \\
\hline Arcyria globosa Schwein. & 3 & 2 & 1 & $\mathrm{O}$ & $7.04 \pm 0.07,6.91-7.12$ \\
\hline Collaria arcyrionema (Rostaf.) Nann.-Bremek. ex Ing & 1 & 1 & 0 & $\mathrm{R}$ & 6.59 \\
\hline Comatricha pulchella (C. Bab. \& Berk.) Rostaf. & 2 & 0 & 2 & $\mathrm{O}$ & $7.34 \pm 0.06,7.28-7.41$ \\
\hline Comatricha rubens Lister & 1 & 0 & 1 & $\mathrm{R}$ & 6.70 \\
\hline Comatricha tenerrima (M.A. Curtis) G. Lister & 7 & 2 & 5 & $\mathrm{C}$ & $7.18 \pm 0.11,6.80-7.57$ \\
\hline Cribraria lepida Meylan & 2 & 2 & 0 & $\mathrm{O}$ & $7.29 \pm 0.18,7.10-7.47$ \\
\hline Cribraria violacea $\mathrm{Rex}$ & 4 & 2 & 2 & $\mathrm{C}$ & $7.68 \pm 0.13,7.49-8.06$ \\
\hline Didymium nigripes (Link) Fr. & 4 & 3 & 1 & $\mathrm{O}$ & $6.94 \pm 0.44,6.50-7.39$ \\
\hline Didymium squamulosum (Alb. \& Schwein.) Fr. & 25 & 10 & 15 & A & $7.26 \pm 0.08,6.50-8.07$ \\
\hline Didymium verrucosporum Welden & 1 & 0 & 1 & $\mathrm{R}$ & 7.16 \\
\hline Diachea bulbillosa (Berk. \& Broome) Lister ex Penzig & 1 & 1 & 0 & $\mathrm{R}$ & 7.36 \\
\hline Diachea leucopodia (Bull.) Rostaf. & 2 & 2 & 0 & $\mathrm{R}$ & 6.79 \\
\hline Diderma effusum (Schwein.) Morgan & 8 & 2 & 6 & A & $7.06 \pm 0.18,6.35-7.84$ \\
\hline Diderma hemisphaericum (Bull.) Hornem. & 52 & 31 & 21 & A & $7.22 \pm 0.05,6.35-8.07$ \\
\hline Dianema harveyi Rex & 1 & 1 & 0 & $\mathrm{R}$ & 7.05 \\
\hline Echinostelium minutum de Bary & 1 & 0 & 1 & $\mathrm{R}$ & 6.90 \\
\hline Hemitrichia minor G. Lister & 2 & 1 & 1 & $\mathrm{O}$ & $7.25 \pm 0.36,6.90-7.61$ \\
\hline Hemitrichia pardina (Minakata) B. Ing & 1 & 1 & 0 & $\mathrm{R}$ & 7.42 \\
\hline Hemitrichia serpula (Scop.) Rostaf. & 1 & 1 & 0 & $\mathrm{R}$ & 7.88 \\
\hline Lamproderma scintillans (Berk \& Broome) Morgan & 2 & 1 & 1 & $\mathrm{O}$ & $7.47 \pm 7.34-7.59$ \\
\hline Perichaena chrysosperma (Currey) Lister & 43 & 21 & 22 & A & $7.26 \pm 0.06,6.10-7.84$ \\
\hline Perichaena corticalis (Batsch) Rostaf. & 4 & 1 & 3 & $\mathrm{C}$ & $7.09 \pm 0.07,6.35-8.06$ \\
\hline Perichaena depressa Libert & 22 & 10 & 12 & A & $7.24 \pm 0.10,6.35-8.06$ \\
\hline Perichaena dictyonema Rammeloo & 15 & 8 & 7 & A & $7.33 \pm 0.17,6.10-8.07$ \\
\hline Perichaena pedata (Lister \& G. Lister) G. Lister & 21 & 14 & 7 & A & $7.32 \pm 0.08,6.67-8.07$ \\
\hline Perichaena vermicularis (Schwein.) Rostaf. & 10 & 2 & 8 & A & $7.23 \pm 0.10,6.70-7.65$ \\
\hline Physarum album (Nees) Fr. & 3 & 2 & 1 & $\mathrm{O}$ & $7.53 \pm 0.13,7.30-7.74$ \\
\hline Physarum bitectum G. Lister & 2 & 1 & 1 & $\mathrm{O}$ & $7.11 \pm 0.12,6.99-7.53$ \\
\hline Physarum bivalve Pers. & 1 & 1 & 0 & $\mathrm{R}$ & 7.49 \\
\hline Physarum cinereum (Batsch) Pers. & 8 & 4 & 4 & $\mathrm{C}$ & $7.46 \pm 0.27,6.10-7.84$ \\
\hline Physarum compressum Alb. \& Schwein. & 2 & 1 & 1 & $\mathrm{O}$ & $7.26 \pm 0.27,6.99-7.53$ \\
\hline Physarum decipiens M.A. Curtis & 1 & 0 & 1 & $\mathrm{R}$ & 7.59 \\
\hline Physarum globuliferum (Bull.) Pers. & 5 & 1 & 4 & $\mathrm{C}$ & $7.15 \pm 0.06,6.97-7.35$ \\
\hline Physarum leucophaeum Fr. & 1 & 1 & 0 & $\mathrm{R}$ & 7.54 \\
\hline Physarum melleum (Berk. \& Broome) Massee & 12 & 7 & 5 & A & $7.07 \pm 0.11,6.67-7.64$ \\
\hline Physarum oblatum T. Macbr. & 1 & 0 & 1 & $\mathrm{R}$ & 7.6 \\
\hline Physarum pusillum (Berk. \& M.A. Curtis) G. Lister & 2 & 1 & 1 & $\mathrm{R}$ & 7.48 \\
\hline Stemonitis fusca Roth & 1 & 0 & 1 & $\mathrm{R}$ & 7.4 \\
\hline Number of records & 335 & 166 & 169 & & \\
\hline Number of species & 42 & 34 & 33 & & \\
\hline Number of genera & 14 & 12 & 11 & & \\
\hline Taxonomic diversity index & & 2.83 & 3.00 & & \\
\hline
\end{tabular}


Table 2. Comparison of the AIC and BIC values for the five SAD models fitting the myxomycete abundance data from the two municipalities of Laguna.

\begin{tabular}{lcccc}
\hline & \multicolumn{2}{c}{ Los Baños } & \multicolumn{2}{c}{ Calauan } \\
\hline Model & AIC & BIC & AIC & BIC \\
Null & 124.19 & 124.19 & 112.26 & 112.26 \\
Preemption & 118.57 & 120.10 & 106.77 & 108.26 \\
Lognormal & 109.85 & 112.9 & 107.54 & 110.53 \\
Zipf & 109.04 & 112.09 & 111.34 & 114.33 \\
Mandelbrot & 105.73 & 110.31 & 103.09 & 107.58 \\
\hline
\end{tabular}

Taxonomic diversity and species diversity

Based on the taxonomic diversity index (Table 1), Los Baños (2.83) was found to be more taxonomically diverse than Calauan (3.00). This was evident from the 34 identifyable species belonging to 12 genera in Los Baños whereas 33 species belonging to 11 genera were reported in Calauan. In terms of species diversity, using the collecting plots as the sampling unit, a clear trend was observed from the three species diversity indices presented herein as box plots since all showed higher values for Los Baños than Calauan (Fig. 4). However, the mean values for all the three species diversity indices did not show any significant difference between the two municipalities $(\mathrm{p}>0.05)$.
Figure 3. Species abundance distribution curves of five models in accordance to the concept of Wilson (1991). The curves show the ranked abundant species (x-axis) and the relative abundance (y-axis).

Figure 4. Boxplot showing the three different species diversity indices between the two municipalities.

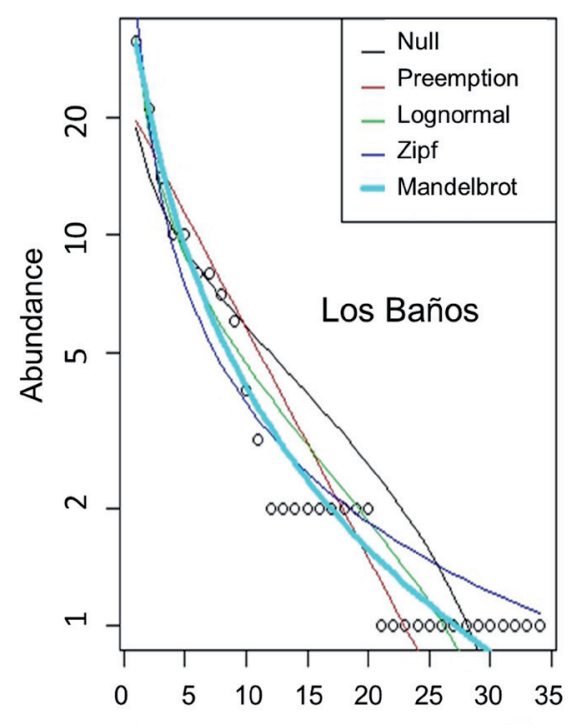

Rank

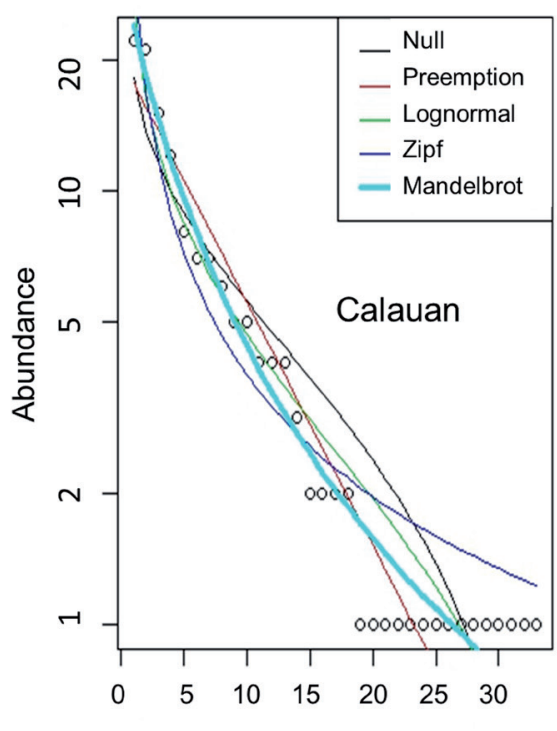

Rank
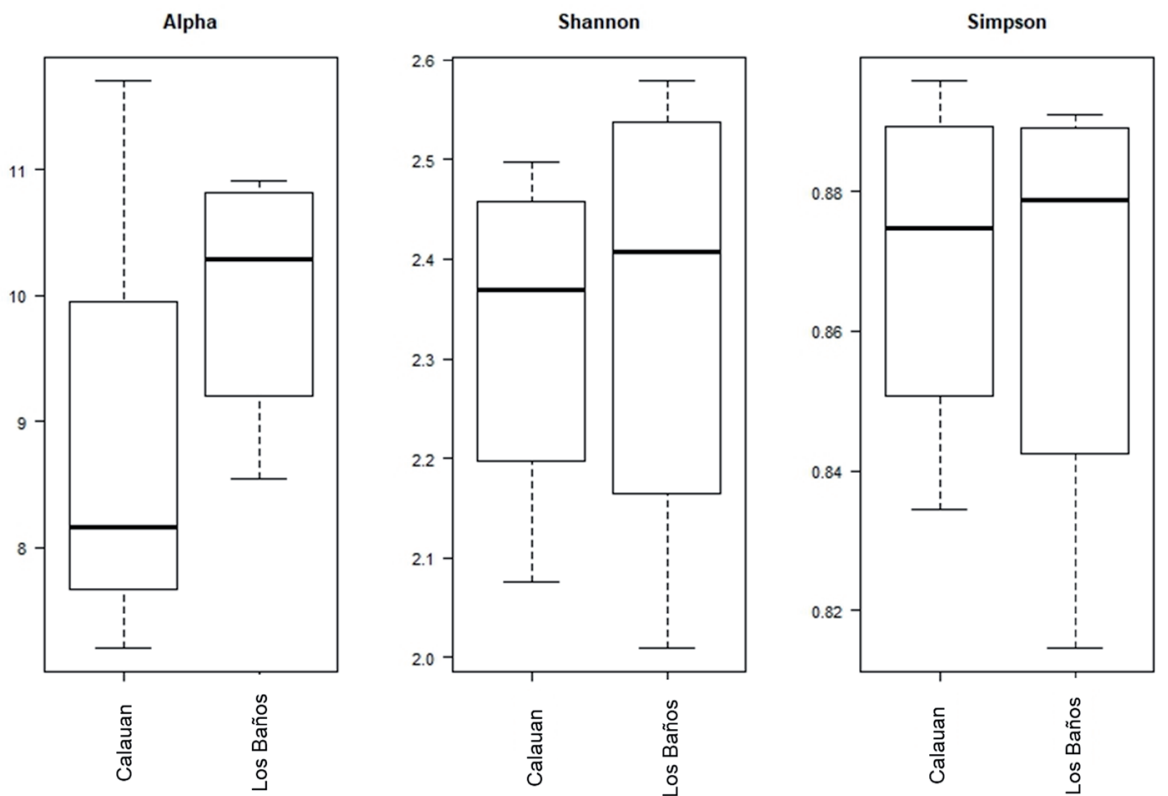

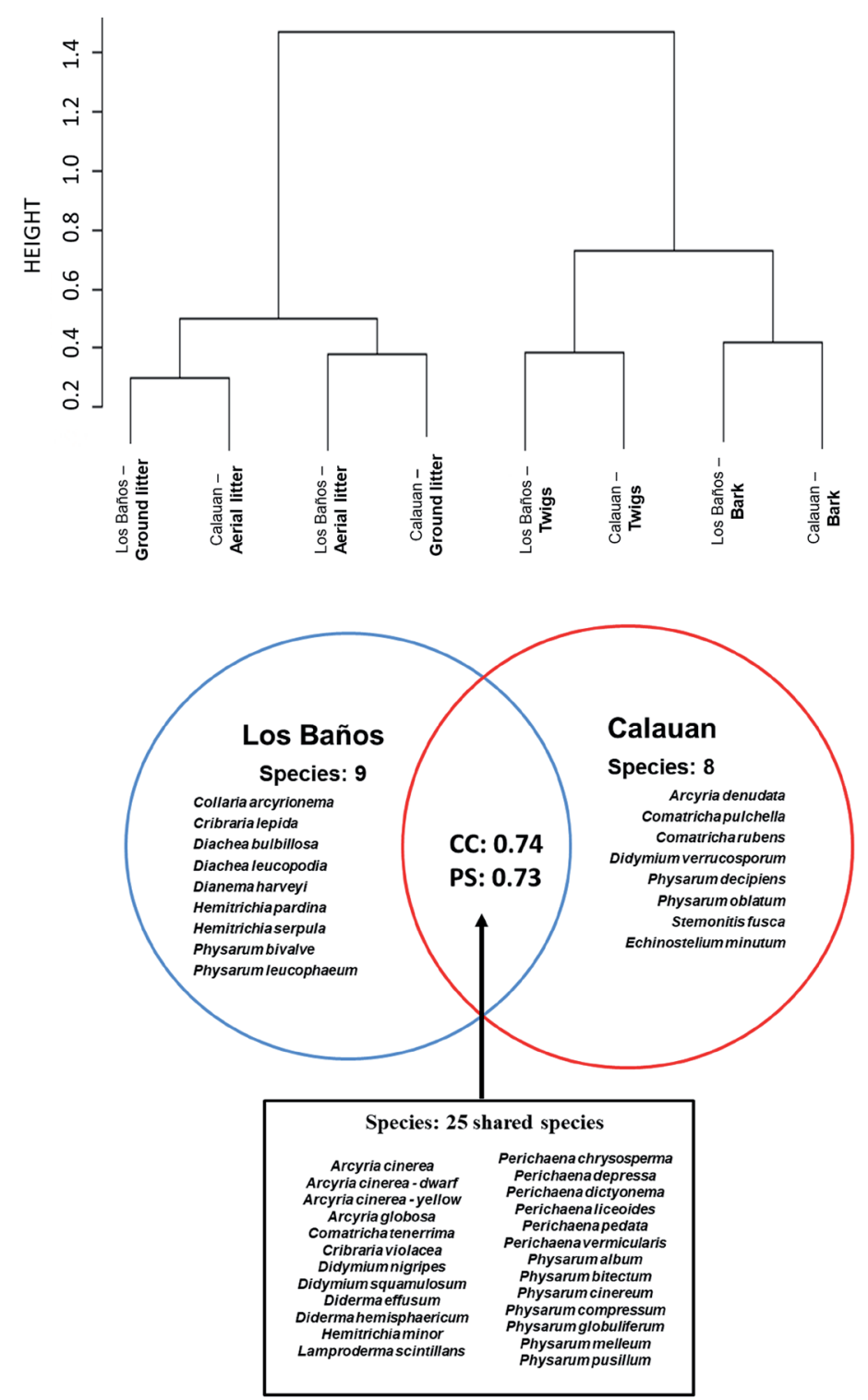

Figure 5. Cluster analysis of Laguna myxomycete samples using the Bray Curtis index.
Figure 6. Venn diagram showing the distribution of the 42 myxomycetes species reported in this study and the values of the coefficient of community (CC) which considers only the presence or absence of myxomycete species between the two municipalities and the percentage similarity (PS) which takes into consideration not only the presence or absence but also the relative abundance.

\section{Community analysis}

Cluster analysis based on Bray Curtis similarity (Fig. 5) showed that regardless of municipality, there is a clear delineation of the grouping of leaf litter substrates (aerial and ground) and wood substrates (twigs and bark). Comparing the composition for each municipality, the generated Venn diagram (Fig. 6) showed high number of shared species ( 25 species $[60 \%])$ and this was further ascertained by the relatively high values of CC (0.74) and PS (0.73) index. For Los Baños and Calauan, 9 species $(21 \%)$ and 8 species $(19 \%)$ were reported to appear only on those municipalities, respectively.

\section{Discussion}

Early reports about myxomycete occurrences in the province of Laguna, Philippines were carried out by Uyenco (1973) and Reynolds (1981). These studies have shown Laguna as an ideal area for ecosystems where myxomycetes could flourish. However, the province is facing a number of environmental threats caused by the rapid population growth and urban development leaving many primary and secondary old growth forests in the area to be fragmented. In 1999, housing projects were built in Calauan by the National Housing Authorities (NHA) as part of the ongoing government projects for illegal settlers living in river banks. From then on numerous projects occurred in the municipality, causing drastic changes in forest structures. Meanwhile, unlike Calauan, Los Baños has been experiencing gradual changes due to some restrictions arranged by the government. However, rapid population growth still exists in the municipality resulting in the establishment infrastructure and increasing demand for resources. All these fast-paced changes may affect myxomycete communities. Though numerous studies have been conducted in the province, there are gaps to be filled. Therefore, this case study is conducted to assess not only the unexplored forest patches in Laguna but also to update the myxomycete profile for this area. 
Evidently, the relatively high success rate $(80 \%)$ among the moist chamber cultures confirms the effectiveness of the set-up in conducting rapid diversity assessments (Macabago et al. 2016, Dagamac et al. 2017c) in tropical conditions wherein fructification is considered to be challenging (Dagamac et al. 2012, Shchepin et al. 2017). From these moist chamber cultures, 42 identifiable morphospecies are reported. Interestingly, Cribraria lepi$d a$ is a new record for the province and for the Philippines. This is surprising, since it is mostly reported in temperate zones such as Switzerland (Meylan 1927), Germany (Neubert et al. 1993) and questionably in USA (Martin and Alexopoulos 1969). It was first recorded for the Neotropics when the first intensive study for cacti and succulent plants was conducted in Mexico (Estrada-Torres et al. 2009). However, this is not the first occurrence of C. lepida in the Southeast Asian region since it was first reported in Southern Vietnam by Novozhilov et al. (2017) and recently reported in Thai Nguyen City, Northern Vietnam by Redeña-Santos et al. (2018).

Similar factors of microenvironments such as $\mathrm{pH}$ of the substrate, moisture, and the presence of other microorganisms may have influenced the fruiting body occurrence since abundantly occurring species such as Arcyria cinerea, Diderma hemisphaericum, and Diderma effusum have been also reported in other areas of the Philippines [Mt. Arayat National park (Dagamac et al. 2014), Lubang Island, (Macabago et al. 2012)]. In contrast, species reported to be rare in other similar studies in the Philippines (Dagamac et al. 2012, Rea-Maminta et al. 2015) such as Didymium squamulosum and Perichaena depressa were reported abundant in this study. Moreover, the abundantly occurring lignicolous myxomycete species, Stemonitis fus$c a$, was reported to be rare since only a single record of the species was accounted for this study. Nonetheless, the dataset for both of the two municipalities fit in the steep gradient Mandelbrot model for species abundance distribution, wherein the model accounts that rare species have larger costs to invade the community because they are dependent on previous physical conditions and previous species presence (Wilson 1991). This means that rare species have higher probability of invading another community, since lower competition for resources and space are expected in other communities. Another recent myxomycete study in Bohol Island, Philippines (Macabago et al. 2017) showed a difference in species abundance distribution model after the 7 collecting communities followed the Zipf model and the only monotypic plantation and reef woodland follows the pre-emption model. Perhaps, similar to the findings in the temperate zones (Big Bend National Park, Ndiritu et al. 2009, Altay Mountains, Novozhilov et al. 2010), the variations in terms of vegetation types among different collecting localities in the Philippines played a role in these differences in occurrences and species abundance distributions.
Comparison of the diversities of the two municipalities

Calauan has clearly showed lower species richness than Los Baños based on the trends generated from the rarefaction values $($ Calauan $=34.7$, Los Baños $=36.0)$ of the species accumulation curve (Fig. 2) and Fisher's alpha index (Fig. 4). But diversity is not richness alone; several heterogeneity indices (Fig. 4) that also take into consideration the evenness of the distribution for each species and the taxonomic diversity index (Table 1) that was calculated in this study support also higher diversity in Los Baños than in Calauan. Perhaps, this can be explained by two concurring factors: (i) the exposure rate to anthropogenic disturbance (Webster and Jenkins 2005, Lassauce et al. 2011, Dagamac et al. 2015b) and (ii) forest structure (Rojas and Stephenson 2012) of the two municipalities.

Since the forest patches in Los Baños is within the vicinities of managed and monitored landscapes, the level of man-made disturbance is characterized to be moderate, hence, the fragments of secondary old growth forest in Los Baños are composed of plant communities (i.e. herbaceous flowering plants and dipterocarp trees) that are comparatively more heterogeneous than in Calauan which is mostly dominated by weeds and grasses. In addition, the plots in the forest patches in Laguna were established in closed canopy sites. In contrast, the forest patches in Calauan are highly exposed to many economic activities of the locals such as slash and burn farming, logging and grazing of farming animals, making the forests to be described as more disturbed than in Los Baños with mostly new plant communities starting to regenerate, and there is almost no closed canopy from older trees. Furthermore, they are usually found along public infrastructures making the forest to be easily accessible to community settlements and vehicular transports. These patterns were also reported in several studies that showed plant heterogeneity to affect myxomycete diversity in the Tropics (Tran et al. 2006, Alfaro et al. 2015). Comparable study was conducted in southwestern Amazon forest, showing highest diversity in Mirador among the eight areas since it is characterized as an old growth forest (Rojas and Stephenson 2012). Moreover, myxomycete studies in the Philippines, for example in Bicol Peninsula (Dagamac et al. 2017a) and in Puerto Galera (Dagamac et al. 2015b) during the last recent years reported higher diversities in forest patches that are exposed to moderate anthropogenic activities such as trekking or animal domestication (Dagamac et al. 2015b). In concurrence with these other studies, it seems that myxomycetes in fragmented forests in Laguna may also follow the intermediate disturbance hypothesis stating that higher diversity and richness can be seen in areas experiencing intermediate disturbance (Connell 1978). Nonetheless, to prove this, it would be interesting to conduct further studies in Laguna that would look into the differences in a disturbance gradient: in a primary undisturbed forest and in an extremely disturbed forest, the diversities of myxomycete communities are expected to be lower than in moderately disturbed forest fragments. 


\section{Community structure}

Cluster analysis (Fig. 5) demonstrates that regardless of the sites (municipalities), myxomycete assemblages in Laguna are influenced by their substrate. This confirms that some myxomycetes have substrate preference. Examples are Stemonitis fusca, Comatricha nigra and Physarum decepiens that are known to occur mostly on wood and Hemitrichia serpula and Perichaena chrysosperma which prefer to thrive on leaf surfaces. In terms of the similarities of their myxomycete communities, high similarity $(\mathrm{CC}=0.74$ and $\mathrm{PS}=0.73)$ indicates high number of shared species (Fig. 6, 25 species) by both municipalities. Furthermore, almost all myxomycete species found only in Los Baños and Calauan are categorized to be rare. However, when the abundance index between the shared species of the two municipalities was assessed, the myxomycete species were classified to be abundant, or common. Evidently, based on this result, rare species can either (i) stay in a community where life is more stable but no chances of invasion due to high competition or (ii) transfer to another community where chances of survival are lower as well as competition, and thus invasion is more possible. Perhaps, this can be explained by different scenarios of dispersal.

On one hand, dispersal can be caused by biological agents. An example is the active movement of people. This scenario is likely to occur between Los Baños and Calauan since they are in close proximity with each other (Fig. 1). Since most myxomycete spores are airborne (Kamono et al. 2009), it is assumed that they could easily attach to human garments, i.e. clothes and footwear, or directly to skin and hair because of their relatively small diameters. Lang (2001) reported that cotton materials harboured and dispersed fungal spores more efficiently than other kinds of fabrics. As such, spores of myxomycetes could also follow the similar process due to their comparable sizes. This means that humans could become agents of long-distance spore dispersal (Ansong 2015). Additionally, insects and other arthropods could also serve as dispersal agents (Lacey 1996) either by ingestion (Keller and Smith 1978) or by specialized structure (Stephenson and Stempen 1994). For example, as tiny slime mold beetles (e.g., Anisotoma, Agathidium) brush against the fruiting bodies, spores are released and cover the insect body (Stephenson and Stempen 1994, Wheeler 1984ab). On the other hand, abiotic or natural environmental factors can also cause wide range dispersal of spores. For instance, the spores could travel through wind since even a slight breeze can disperse these spores more than $1 \mathrm{~km}$ distance (Stephenson et al. 2008). This is supported by the British mycologist Berkeley (1857) who has concluded that "trade winds carry spores of fungi mixed with their dust, which may have travelled thousands of miles before they are deposited".

However, these dispersal scenarios are greatly dependent on three critical parameters (Schnittler et al. 2017): (i) the spore size, following the assumption that velocities of myxomycete spores follow the velocities calculated using Stoke's law (Tesmer and Schnittler 2007) and that smaller spores are more capable of dispersing over long distances than larger spores; (ii) spore origin, since higher starting point means longer dispersal like in the case of aerial litter (Schnittler et al. 2006) and (iii) spore ornamentation since the more reticulated the spores are, the higher hydrophobic effect and refractivity to the water surface (Hoppe and Schwippert 2014). Given these critical parameters, the abundantly occurring taxa i.e., Arcyria or Stemonitis are most likely to be easily dispersed. Similar with the leptokurtic dispersal curves of pollens (Ottewell et al. 2012), fungal spores (Penet et al. 2014), or spores of bryophytes (Pohjamo et al. 2006), myxomycetes may be able to reach distant microhabitats with adequate high density of microorganisms between municipalities of Los Baños and Calauan. However, no quantitative dispersal models have been developed for myxomycetes and this aspect of dispersal ecology in the tropics requires further investigations.

Acknowledgements: JLMB, LJQA and KJA-R would like to thank the SusEnMan (Sustainable Environmental Management) Project (DAAD Project 57218030) headed by Prof. Dr. W. Steingrube for the grant given for their 3-month research internship. The authors would also like to acknowledge Prof. M. Schnittler and the International Office (University of Greifswald) for the financial support for the field collection and laboratory materials. Moreover all authors extend their gratitude to the three anonymous reviewers who evaluated and gave constructive feedbacks that help improved this manuscript.

\section{References}

Alfaro, J.R.D., D.L.I.M. Alcayde, J.B. Agbulos, N.H.A. Dagamac and T.E.E. dela Cruz. 2015. The occurrence of myxomycetes from a lowland montane forest and agricultural plantations of Negros Occidental, Western Visayas, Philippines. Fine Focus $1: 7-20$.

Almadrones-Reyes, K.J.A. and N.H.A. Dagamac. 2018. Predicting local habitat suitability in changing climate scenarios: Applying species distribution modelling for Diderma hemisphaericum. Curr. Res. Environ. Appl. Mycol. 8:492-500.

Ansong, M., C. Pickering and J.M. Arthur. 2015. Modelling seed retention curves for eight weed species on clothing. Austral. Ecol. 40: 765-774

Berkeley, M.J. 1857. Introduction to Cryptogamic Botany. Bailliere, London.

Bray, J.R. and J.T. Curtis. 1957. An ordination of upland forest communities of Southern Wisconsin. Ecol. Monog. 27:325-349.

Broennimann, O., M.C. Fitzpatrick, P.B. Pearman, B. Petitpierre, L. Pellissier, N.G. Yoccoz, W. Thuiller, M.J. Fortin, C. Randin, N.E. Zimmermann, C.H. Graham and A. Guisan. 2012. Measuring ecological niche overlap from occurrence and spatial environmental data. Global Ecol. Biogeogr. 21:481-497.

Connell, J.H. 1978. Diversity in tropical rain forest and coral reefs. Science 199:1302-1310.

Corpuz, I.R., C.C. Martinez, K.N. Petilla, J.C. Baranda, A. Buaya and T.E.E. dela Cruz. 2012. Occurrence and diversity of myxomycetes (plasmodial slime molds) in Mt. Palay-palay National Park, Cavite, Philippines. Acta Manilana 60:57-65.

Dagamac, N.H.A. and T.E.E. dela Cruz. 2015. Myxomycete research in the Philippines: Updates and opportunities. Mycosphere 6: 784-795. 
Dagamac, N.H.A., D.V. Leontyev and T.E.E. dela Cruz. 2010. Corticolous myxomycetes associated with Samanea saman (Jacq.) Merr. collected from different sites in Luzon Island, Philippines. The Philippine Biota 43:2-15.

Dagamac, N.H.A., S.L. Stephenson and T.E.E. dela Cruz. 2012. Occurrence, distribution and diversity of myxomycetes (plasmodial slime molds) along two transects in Mt. Arayat National Park, Pampanga, Philippines. Mycology 3:119-26.

Dagamac, N.H.A., S.L. Stephenson and T.E.E. dela Cruz. 2014. The occurrence of litter myxomycetes at different elevations in Mt. Arayat, National Park, Pampanga, Philippines. Nova Hedwigia 98:187-196.

Dagamac, N.H.A, M.A.D. Rea-Maminta and T.E.E. dela Cruz. 2015a. Plasmodial slime molds of a tropical karst forest, Quezon national Park, the Philippines. Pac. Sci. 69:407-418.

Dagamac, N.H.A., M.A.D. Rea-Maminta, N.S. Batungbacal, J. Soo Hyun, C.R.T. Bulang, A.G.R. Cayago and T.E.E. dela Cruz. 2015b. Diversity of plasmodial slime molds (myxomycetes) in coastal, mountain, and community forests of Puerto Galera, Oriental Mindoro, the Philippines. J. Asia-Pac. Biodivers. $8: 322-329$

Dagamac, N.H.A., T.E.E. dela Cruz and M.A.D. Rea-Maminta. 2017a. Rapid assessment of myxomycete diversity in Bicol Peninsula. Nova Hedwigia 104:31-46.

Dagamac, N.H.A., Y.K. Novozhilov, S.L. Stephenson, C. Lado, C. Rojas, T.E.E. dela Cruz, M. Unterseher and M. Schnittler. $2017 \mathrm{~b}$. Biogeographical assessment of myxomycetes assemblages from Neotropical and Asian Paleotropical forests. J. Biogeogr. 44: 1524-1536.

Dagamac, N.H.A., M. Hoffmann, Y.K. Novozhilov and M. Schnittler. 2017c. Myxomycetes from the highlands of Ethiopia. Nova Hedwigia 104:111-127.

Dela Cruz T.E.E., Rea M.A.D., Tran H.T.M., Ko Ko T.W. and Stephenson S.L. 2014. A comparative species listing of myxomycetes from tropical (Philippines) and temperate (United States) forests. Mycosphere 5(2):299-311.

Dogma, I.J. 1975. Of the Philippine mycology and lower fungi. Kalikasan Phil. J. Biol. 4:69-105.

Estrada-Torres, A., D. Wrigley de Basanta, E. Conde and C. Lado. 2009. Myxomycetes associated with xerophyllous scrubland of the Tehuacan-Cuicatan Valley Biosphere Reserve, Mexico. Fungal Divers. 36:17-56.

Feest, A. 1987. The quantitative ecology of soil mycetozoa. Prog. Protistol. 2:331-361.

Fiore-Donno, A.M., S.L. Nikolaev, M. Nelson, J. Pawlowski, T. Cavalier-Smith and S.L. Baldauf. 2010. Deep phylogeny and evolution of slime moulds (Mycetozoa). Protist 161:55-70.

Foissner, W. 1999. Protist diversity: estimates of the near imponderable. Protist 150:363-368

Kamono, A., H. Kojima, J. Matsumoto, K. Kawamura and M. Fukui. 2009. Airborne myxomycete spores: detection using molecular techniques. Naturwissenschaften 96:147-151.

Keller, H.W. and D.M. Smith. 1978. Dissemination of myxomycete spores through the feeding activities (ingestion-defecation) of an acarid mite. Mycologia 70:1239-1241.

Keller, H.W. and K.L. Snell. 2002. Feeding activities of slugs on myxomycetes and fungi. Mycologia 94:757-60.

Keller, H.W., C.M. Kilgore, S.E. Everhart, G.J. Carmack, C.D. Crabtree and A.R. Scarborough. 2008. Myxomycete plasmodia and fruiting bodies: Unusual occurrences and user friendly study techniques. Fungi 1:24-37.
Kuhn, R.V., A.O.M. Javier, C.P. Rodillas, C.M. Parra, L.H.M. Corpuz, A.T. Buaya and T.E.E. dela Cruz. 2013. Diveristy of plasmodial myxomycetes from Anda island, Pangasinan, Philippines. Biotropia 20:1-9.

Hoppe, T. and W.W. Schwippert. 2014. Hydrophobicity of myxomycete spores: An undescribed aspect of spore ornamentation. Mycosphere 5:601-606.

Lacey, J. 1996. Spore dispersal - its role in ecology and disease: the British contribution to fungal aerobiology. Mycol. Res. 100: 641-660.

Lang, S.S. 2001. Cotton clothes found to be leading carrier of fungal spores, a scourge to some hospital patients with damaged immune systems. http://news.cornell.edu/stories/2001/02/cottonclothes-carry-fungal-spores-hospitals. (Accessed on 24.06.18).

Lado, C. 2005-2018. An online nomenclatural information system of Eumycetozoa. Real Jardín Botánico de Madrid, CSIC, Madrid, Spain. Available from: http://www.nomen.eumycetozoa.com (Accessed 14.06.2018)

Lassauce, A., Y. Paillet, H. Jactel and C. Bouget. 2011. Deadwood as a surrogate for forest biodiversity: Meta-analysis of correlations between deadwood volume and species richness of saproxylic organisms. Ecol. Indic. 11:1027-1039.

Macabago, S.A.B., T.E.E. dela Cruz and S.L. Stephenson. 2012. First records of myxomycetes from Lubang Island, occidental Mindoro, Philippines. Sydowia 64:109-118.

Macabago, S.A.B., N.H.A. Dagamac, T.E.E. dela Cruz and S.L. Stephenson. 2017. Implications of the role of dispersal on the occurrence of litter-inhabiting myxomycetes in different vegetation types after a disturbance: a case study in Bohol Islands, Philippines. Nova Hedwigia 104:221-236.

Macabago, S.A.B., S. L. Stephenson and T.E.E. dela Cruz. 2016. Diversity and distribution of myxomycetes in coastal and mountain forests of Lubang Islands, Occidental Mindoro, Philippines. Mycosphere 7:18-29.

Massingill, J.M. and S.L. Stephenson. 2013. Myxomycetes appearing in moist chamber cultures on samples of bark and wood collected from coarse woody debris. Mycosphere 4(3):627-633.

Martin, G. and C.J. Alexopoulos. 1969. The Myxomycetes. University of Iowa Press, Iowa.

Martiny, H.J.B., B.J.M. Bohannan, J.H. Brown, R.K. Colwell, J.A. Fuhrman, J.L. Green, M.C. HornerDevine, M. Kane, J.A. Krumins, C.R. Kuske, P.J. Morin, S. Naeem, L. Øvreås, A.L. Reysenbach, V.H. Smith and J.T. Staley, 2006. Microbial biogeography: putting microorganisms on the map. Nat. Rev. Microbiol. 4:102-112.

McGill, B., R. Etienne, J. Gray, D. Alonso, M.J. Anderson, H.K. Benecha, M. Dornelas, B.J. Enquist, J.L. Green, F. He, A.H. Hurlbert, A.E. Magurran, P.A. Marquet, B.A. Maurer, A. Ostling, C.U. Soykan, K.I. Ugland and E.P. White. 2007. Species abundance distribution: moving beyond single prediction theories to integration within an ecological framework. Ecol. Lett. 10: 995-1015.

Meylan, C. 1927. Recherches sur les Myxomycètes du Jura en 192526. Bull. Soc. vaud. Sci, Nat. 56:319-328.

Moreno, G., D.W. Mitchell, S.L. Stephenson and T.E.E. dela Cruz. 2009. A new species of Craterium (Myxomycetes) with reticulate spores. Bol. Soc. Micol. Madr. 33:175-200.

Ndiritu, G.G., W. F. Spiegel and S. L. Stephenson. 2009. Distribution and ecology of the assemblages of myxomycetes associated with major vegetation types in Big Bend National Park, USA. Fungal Ecol. 2:168-183.

Neubert, H., W. Nowotny and K. Baumann. 1993. Die Myxomyceten. Band 1. Karlheinz Baumann Verlag, Gomaringen. 
Novozhilov Y.K., D.A. Erastova, O.N. Shchepin and M. Shnittler. 2017. Myxomycetes associated with monsoon lowland tropical forests in southern Vietnam. Nova Hedwigia 104:143-182.

Novozhilov, Y.K., M. Schnittler, A. Vlasenko, V.A. Anastasia and F.A. Konstantin. 2010. Myxomycete diversity of the Altay Mountains (southwestern Siberia, Russia). Mycotaxon 111:91-94.

Ottewell, K., E. Grey, F. Castillo and J. Karubian. 2012. The pollen dispersal kernel and mating system of an insect-pollinated tropical palm, Oenocarpus bataua. Heredity 109:332-339.

Penet, L., S. Guyader, D. Pétro, M. Salles and F. Bussière. 2014 Direct splash dispersal prevails over indirect and subsequent spread during rains in Colletotrichum gloeosporioides infecting yams. PLoS One 9:e115757.

Pohjamo, M., S. Laaka-Lindberg, O. Ovaskainen and H. Korpelainen. 2006. Dispersal potential of spores and asexual propagules in the epixylic hepatic Anastrophyllum hellerianum. Evol. Ecol. 20: 415-430.

Rea-Maminta, M.A.D., N.H.A. Dagamac, F.Z. Huyop, R.A. Wahab and T.E.E. dela Cruz. 2015. Comparative diversity and heavy metal biosorption of myxomycetes from forest patches on ultramafic and volcanic soils. Chemistry and Ecology 31:741-753.

Redeña-Santos, J.C., J.A.U. Dunca, D.V. Thao and N.H.A Dagamac. 2017. Myxomycetes occurring on selected agricultural leaf litters. Studies in Fungi 2:171-177.

Redeña-Santos, J.C., D.V. Thao, M. Schnittler and N.H.A. Dagamac. 2018. The first report of composition and occurrence of myxomycetes assemblages in protected and unprotected plantation forests: a comparative study in Thai Nguyen City, Northern Vietnam. Plant Ecol. Evol. 151:231-240.

Reynolds, D.R. 1981. Southeast Asian myxomycetes II. Philippines. Phil. J. Biol. 10:127-150.

Rojas, C. and S.L. Stephenson. 2013. Myxomycete ecology along an elevational gradient on Cocos Island, Costa Rica. Fungal Divers. 29:117-127.

Rojas, C. and R.G. Doss. 2014. Does habitat loss affect tropical myxomycetes. Mycosphere 5:692-700.

Rojas, C. and S.L. Stephenson. 2012. Rapid assessment of the distribution of myxomycetes in a southwestern Amazon forest. Fungal Ecol. 5:726-733.

Rojas, C., M. Schnittler, D. Biffi and S.L. Stephenson. 2008. Microhabitat and niche separation in species of Ceratiomyxa. Mycologia 100:843-850.

Schnittler, M. 2000. Foliicolous liverworts as a microhabitat for Neotropical Myxomycetes. Nova Hedwigia 72:259-270.

Schnittler, M, N.H.A. Dagamac and Y.K. Novozhilov. 2017. Biogeographical patterns in myxomycetes. In S.L. Stephenson and C. Rojas (eds.), Myxomycetes: Biology, Systematics, Biogeography and Ecology. Academic Press, San Diego. pp. 299-331.
Schnittler, M., M. Unterseher and J. Tesmer. 2006. Species richness and ecological characterization of myxomycetes and myxomycete-like organisms in the canopy of a temperate deciduous forest. Mycologia 98:223-232.

Shchepin, O.N., N.H.A Dagamac, O.M. Sanchez, Y.K. Novozhilov, M. Schnittler and I.V. Zemlyanskaya. 2017. Mycosphere 8: 1904-1913.

Soberón, J. 2007. Grinnellian and Eltonian niches and geographic distributions of species. Ecol. Lett. 10:1115-1123.

Stephenson, S.L. 1988. Distribution and ecology of myxomycetes in temperate forests I. Patterns of occurrence in the upland forests of southwestern Virginia. Can. J. Bot. 66:2187-2207.

Stephenson, S.L. 2011. From morphological to molecular: studies of myxomycetes since the publication of the Martin and Alexopoulos (1969) monograph. Fungal Divers. 50:21-34.

Stephenson, S.L. and H. Stempen. 1994. Myxomycetes: A Handbook of Slime Molds. Timber Press, Portland, OR.

Stephenson, S.L., I. Kalyanasundaram and T. Lakhanpal. 1993. A comparative biogeographical study of myxomycetes in the midappalachians of eastern North America and two regions of India. J. Biogeogr. 20:645-657.

Stephenson S.L., M. Schnittler and Y.K. Novozhilov. 2008 Myxomycete diversity and distribution from the fossil record to the present. Biodivers. Conserv. 17:285-301.

Tesmer, J. and Schnittler, M., 2007. Sedimentation velocity of myxomycete spores. Mycol. Prog. 6:229-234.

Tran, T.M., S.L. Stephenson, K.D. Hyde and O. Mongkolporn. 2006 Distribution and occurrence of myxomycetes in tropical forests in northern Thailand. Fungal Divers. 22:227-242.

Uyenco, F.R. 1973. Myxomycetes of the Philippines. Univ. Phil. Nat. Sci. Res. Cen. Tech. Rep. 12:1-23.

Wilson, B.J. 1991. Methods for fitting dominance/diversity curves J. Veg. Sci. 2:35-46.

Webster, C.R. and M. A. Jenkins. 2005. Coarse woody debris dynamics in the southern Appalachians as affected by topographic position and anthropogenic disturbance history. Forest Ecol. Manag. 217:319-330.

Wheeler, Q. D. 1984a. Evolution of slime mold feeding in leiodid beetles. In: Q. D. Wheeler and M. Blackwell (eds), Fungusinsect Relationships: Perspectives in Ecology and Evolution. Columbia University Press, New York. pp. 446-77.

Wheeler, Q. D. 1984b. Associations of beetles with slime molds: ecological patterns in the Anisotomini (Leiodidae). Bull. Entom. Soc. America. 39:14-18.

Received June 27, 2018 Revised October 31, November 27, 2018 Accepted December 2, 2018 